Tropical Journal of Pharmaceutical Research September 2020; 19 (9): 1903-1910

ISSN: $1596-5996$ (print); 1596-9827 (electronic) (C) Pharmacotherapy Group, Faculty of Pharmacy, University of Benin, Benin City, 300001 Nigeria.

\title{
Ferula asafoetida Linn. is effective for early functional recovery following mechanically induced insult to the sciatic nerve of a mouse model
}

\author{
Syed Kashif Shahid Kamran¹, Azhar Rasul', Haseeb Anwar ${ }^{1}$, Shahzad Irfan', \\ Khizar Sami Ullah², Shoaib Ahmad Malik ${ }^{3}$, Aroona Razzaq ${ }^{1}$, Nimra Aziz', Nady \\ Braidy ${ }^{4}$, Ghulam Hussain ${ }^{1 *}$ \\ ${ }^{1}$ Neurochemicalbiology and Genetics Laboratory (NGL), Department of Physiology, ${ }^{2}$ Department of Zoology, Faculty of Life \\ Sciences, Government College University, Faisalabad, ${ }^{3}$ Department of Biochemistry, Sargodha Medical College, University of \\ Sargodha, Sargodha, Pakistan, ${ }^{4}$ Centre for Healthy Brain Ageing, School of Psychiatry, The University of New South Wales, \\ Sydney, Australia
}

*For correspondence: Email: gh_azer@hotmail.com

Sent for review: 20 November 2019

Revised accepted: 18 August 2020

\begin{abstract}
Purpose: To evaluate the effect of Ferula asafoetida (oleo gum resin powder) on sensory and motor functions retrieval on an induced sciatic nerve injury in a mouse model.

Methods: A mechanical crush was inserted in the sciatic nerve of all the experimental mice after acclimatization. The mice were allocated to four groups; one normal chow group (control, $n=7)$ and three Ferula asafoetida chow groups (each $n=7$ ) of different doses (50, 100 and $200 \mathrm{mg} / \mathrm{kg}$ ). Muscle grip strength, muscle mass, and sciatic functional index were measured to evaluate the motor function regain, while sensory function regain was assessed by hot plate test. Oxidative stress and glycemic levels were measured by biochemical assays.

Results: The findings of this study indicate that Ferula asafoetida $200 \mathrm{mg} / \mathrm{kg}$ has a highly significant ( $p$ $\leq 0.001)$ ameliorating effect in terms of improved grip strength $(77.7 \pm 5.4 \%$ for $200 \mathrm{mg} / \mathrm{kg}$ vs. $46 \pm 5.1$ $\%$ for control), reversal of SFI towards normal ( $-34 \pm 8.1$ for $200 \mathrm{mg} / \mathrm{kg}$ group vs. $-61 \pm 6.1$ for control), decrease in paw withdrawal latency ( $7.10 \pm 0.06 \mathrm{~s}$ for $200 \mathrm{mg} / \mathrm{kg}$ group vs. $15 \pm 0.5 \mathrm{~s}$ for control) on day 12 post-injury, as well as restoration of skeletal muscle mass towards normal. Interestingly, $F$. asafoetida chow $50 \mathrm{mg} / \mathrm{kg}$ and $100 \mathrm{mg} / \mathrm{kg}$ groups also impacted significant $(p<0.01)$ improvement in the ameliorative effect. However, the differences among all treatment groups in ameliorating recovery were not significant $(p>0.05)$. Moreover, comparatively improved $(p<0.0001)$ total antioxidant capacity along with reduced total oxidant status $(p=0.01)$ in the Ferula asafoetida chow $(200 \mathrm{mg} / \mathrm{kg})$ group, indicate the antioxidative effect of this plant. Furthermore, the treated mice $(200 \mathrm{mg} / \mathrm{kg})$ also expressed an improved glycemic level $(p=0.0005)$.

Conclusion: Ferula asafoetida supplementation helps to accelerate both sensory and motor function retrieval following sciatic nerve injury. This improvement is thought to be correlated with the antioxidant capacity of the plant. However, further investigations are required to identify the therapeutic principles responsible for the observed actions.
\end{abstract}

Keywords: Sciatic nerve injury, Ferula asafoetida, Function recovery, Oxidative stress, Biochemical analysis

This is an Open Access article that uses a fund-ing model which does not charge readers or their institutions for access and distributed under the terms of the Creative Commons Attribution License (http://creativecommons.org/licenses/by/4.0) and the Budapest Open Access Initiative (http://www.budapestopenaccessinitiative.org/read), which permit unrestricted use, distribution, and reproduction in any medium, provided the original work is properly credited.

Tropical Journal of Pharmaceutical Research is indexed by Science Citation Index (SciSearch), Scopus, International Pharmaceutical Abstract, Chemical Abstracts, Embase, Index Copernicus, EBSCO, African Index Medicus, JournalSeek, Journal Citation Reports/Science Edition, Directory of Open Access Journals (DOAJ), African Journal Online, Bioline International, Open-J-Gate and Pharmacy Abstracts 


\section{INTRODUCTION}

Peripheral nerve injury (PNI) stands among the most prevalent and complex medical situations that is characterized by a partial or complete functional disability. Effective therapy for a thoroughly perfect restoration of physical activity has been a challenge until now. PNI may be a consequence of road accidents, physical or mechanical traumas, gunshots, bone fractures compressing nearby nerve, etc. Although there is an ability of self-repair in the peripheral nervous system (PNS), this process is terribly sluggish $[1,2]$. In addition to other miscellaneous factors, a very slow regeneration, accompanied with muscular atrophy is found to be the main obstacle to achieving functional recovery [3].

Although a variety of medicinal and surgical approaches are in practice to treat PNI, none of them can lead to a complete restoration of nerve function. Therefore, a perfect recovery of physical function always appears an unbeatable challenge. Plants are considered as a constant and inexhaustible source for the discovery of drug candidates since the beginning. Nowadays, considerable emphasis has been made on figuring out therapeutically effective strategies based on novel bioactive compounds from plants. Even in the modern age, natural compound-based approach is preferred to allopathic drugs in many parts of the world because of their invincible advantages, such as abundant availability, easy accessibility, and minor to no side-effects [3-6]. Therefore, such plant-sourced compounds which are effective enough in speeding up function retrieval, would prove a revolution in the field of medicine [7]. Thus, these natural compounds present an auspicious alternative therapeutic approach.

Ferula asafoetida ( $F$. asafoetida) from Umbelliferae family, is cultivated in most parts of the world, including the Middle East and Indian sub-continents. An oleo-gum-resin, commonly known as asafoetida, is obtained from the exudates of the roots of this plant [7]. Asafoetida has been used as a spice and a folk phytomedicine for centuries. $F$. asafoetida is effective against anxiety, convulsions, epilepsy, peripheral neuropathy, and mood disorders. It is also used as a nerve stimulator and sedative agent [8]. $F$. asafoetida can be a reliable candidate for PNI because of its reported neuroprotective effects. But its role in accelerating function retrieval following $\mathrm{PNI}$ has not been investigated. Therefore, this study was planned to unravel the possible effectiveness of $F$. asafoetida on the rate of functional restoration in an already established rodent model of compression injury.

\section{EXPERIMENTAL}

\section{Animals}

Healthy male albino mice (10 - 12 weeks old, and 28 - $30 \mathrm{~g}$ weight) were procured from the animal facility in GC University, Faisalabad. They were housed in separate rodent cages at ambient room temperature $\left(23 \pm 2{ }^{\circ} \mathrm{C}\right)$, in a humiditycontrolled environment, and a 12 hours light and dark cycle with ad libitum supply of rodent chow diet and drinking water.

The protocols for the use and care of animals in this study were based on the rules provided by the National Institute of Health (NIH) for the use and care of experimental animals [24]. The design of the study was sanctioned by the IRB (Institutional Review Board), GC University Faisalabad (ERB no. 3845).

\section{Collection and processing of plant material}

F. asafoetida (oleo gum resin) was acquired from the market in Faisalabad, Pakistan. The Department of Botany was consulted for the identification of the plant. The plant material was ground and mixed in rodent chow feed at 50, 100 and $200 \mathrm{mg} / \mathrm{kg}$ of body weight $[8,9]$. The dosage was adjusted in such a way that the daily average consumed diet must contain the required dosage of the plant. This was calculated using Eq 1.

$D=W(D d / 1000)$

where $D, W$ and Dd are daily dose, weight of rat, and dose per kg body weight, respectively.

\section{Introduction of nerve injury}

The injury was introduced mechanically to the sciatic nerve following a standard published protocol [10]. The mice were briefly sedated with a ketamine $(70 \mathrm{mg} / \mathrm{kg})$ and xylazine $(5 \mathrm{mg} / \mathrm{kg})$ mixture by giving an intraperitoneal injection. The nerve was made visible and manually crushed with forceps for $15 \mathrm{sec}$ at the mid-thigh region of the right hindlimb. The incisions were sealed with 3 - 4 sutures.

\section{Animal study design}

After introducing the nerve injury, the mice were separated into four groups named as, normal chow (Control, $\mathrm{n}=7$ ), F. asafoetida chow $50 \mathrm{mg}$ $(\mathrm{n}=7), F$. asafoetida chow $100 \mathrm{mg}(\mathrm{n}=7)$, and 
F. asafoetida chow $200 \mathrm{mg}(\mathrm{n}=7)$. From the day of the nerve crush until the end of the study, the control group was given normal rodent feed, while $F$. asafoetida chow groups were offered the feed containing the calculated doses of $F$. asafoetida oleo gum resin. At the termination of the experiment, the mice of all groups were sacrificed using deep anesthesia as mentioned above. Blood was collected for biochemical analyses and skeletal muscles from both Ipsi and Contra hindlimbs were dissected to measure muscle mass ratio.

\section{Assessment of sensory function}

Retrieval of sensory function was assessed by applying thermal stimulus (Hot-plate test) using a hotplate (SCILOGEX MS7-H550-S LED digital $7 \times 7$ Hotplate stirrers). The method was carried out according to the standard protocol described by Haas, 2010 [11]. The mouse was briefly allowed to stand on a hot surface set at $56 \pm 1$ ${ }^{\circ} \mathrm{C}$ in such a manner that the ipsilateral paw would be on the hot surface. The time taken for the withdrawal response (jumping, tapping, or jerking of the paw) was noted. A total of 3 readings were recorded at an interval of $2 \mathrm{~min}$ between successive readings. If the mouse did not respond in $30 \mathrm{sec}$ (cut-off time), the stimulus was terminated to prevent skin burning [6].

\section{Assessment of motor function}

\section{Sciatic functional index (SFI)}

The motor function of all mice was evaluated by assessing SFI. The hind paws of the mouse were painted with non-toxic ink and placed on a wooden track (having a white plain sheet on its surface) to walk towards the darkened box. This enables us to get the paw prints of the mouse on a white sheet,which were analyzed by using the following equation to get SFI (Eq. 2):

SFI $=(-38.3 \times-(E P L-N P L) / N P L)+(109.5 \times(E T S-$ NTS $) /$ NTS $)+(13.3 \times($ EIT-NIT $) / N I T)-8.8$

where print Length $(P L)$ is the distance between the heel and tip of the $3^{\text {rd }}$ toe; the intermediate toes spread (IT) is the distance between the $4^{\text {th }}$ and $2^{\text {nd }}$ toe, and toe spread (TS) is the gaplength between the $1^{\text {st }}$ and $5^{\text {th }}$ toe. The $\mathrm{N}$ indicates the normal paw measurements as NPL, NIT, and NTS, whereas E stands for the experimental paw measurements as EPL, ETS, and EIT [10].

\section{Muscle grip strength}

Grip strength test was carried out according to the procedure elaborated by Hussain et al, 2013 [12]. The grip force $(\mathrm{N})$ of both hind limb muscles (contralateral and ipsilateral to the injury site) was measured using a grip strength meter (Bioseb, Chaville, France). The mean of the triplicate readings was taken.

\section{Biochemical analysis}

\section{Total antioxidant capacity}

Antioxidant capacity is the capability of a biosystem to scavenge the free radicals and associated mal-functionalities. TAC (Total Antioxidant Capacity) assay was performed according to the protocol described earlier [10] to measure the antioxidant capacity in serum samples of all animals.

\section{Total oxidant status (TOS)}

The level of oxidative stress is known to be correlative with the extent of Total Oxidant Status (TOS) within the living system. Using this test, the overall status of the TOS ( $\mu$ mol $\mathrm{H}_{2} \mathrm{O}_{2}$ Equivalent/L) was estimated using the protocol described elsewhere [10].

\section{Random blood glucose}

The glycemic level was analyzed with the help of a glucometer (Accu-check). A blood drop was oozed out from the tail of the mouse and was analyzed by using the method used by Asmat el al, 2016 for glucose level [13].

\section{Statistical analysis}

All results are presented as mean \pm SEM. Data were statistically analyzed using GraphPad Prism (version 8.4.2). ANOVA was used to compare the mean of all groups, followed by Tukey's multiple comparisons test. For statistical significance, a value of $p<0.05$ was assumed.

\section{RESULTS}

\section{Impact of $F$. asafoetida on feed intake and body mass}

The daily feed intake was measured throughout the experimental period. A statistically nonsignificant effect $(p=0.23)$ of diet consumption patterns was discovered among all groups. Tukey's multiple comparisons test did not reveal any significant differences among any pair or groups on any day (Figure $1 \mathrm{~A}$ ). It indicates that

Trop J Pharm Res, September 2020; 19(9): 1905 
the $F$. asafoetida addition in the animal feed did not alter the taste of the food, and clearly depicts that the obtained results were dependent on the presence of $F$. asafoetida in the feed. In addition, the daily bodyweight of every animal was recorded, and no statistically significant difference $(p>0.99)$ was noted among all groups on any given day. This indicates that all selected doses of $F$. asafoetida were safe and did not cause any harmful changes in body metabolism (Figure $1 \mathrm{~B}$ ).

(A)

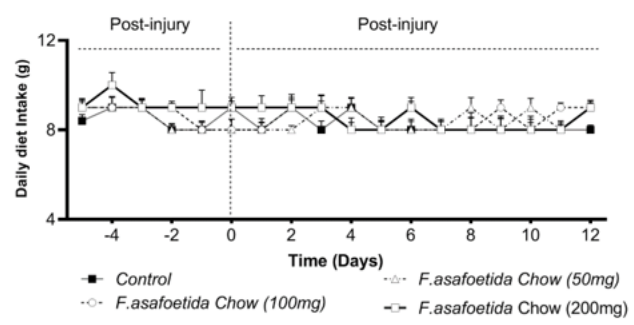

(B)

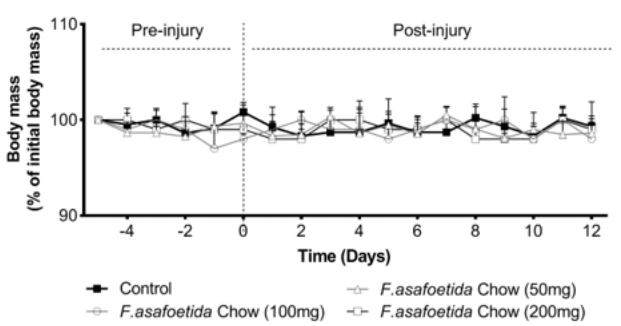

Figure 1: Effect of $F$. asafoetida on daily feed intake (A) and body mass (B). Results are mean \pm SEM; (A) Time course of feed intake in animals fed on normal chow (control $n=7), F$. asafoetida chow 50mg $(n=7)$, $100 \mathrm{mg}(\mathrm{n}=7)$ and $200 \mathrm{mg}(\mathrm{n}=7)$. Two-way repeated measure ANOVA, along with Tukey's multiple comparison test indicated non-significant differences $(p=0.23)$ among all the groups. (B) Time course of body mass of mice served with normal chow (control $n$ $=7), F$. asafoetida chow $50 \mathrm{mg}(\mathrm{n}=7), 100 \mathrm{mg}(\mathrm{n}=7)$ and $200 \mathrm{mg}(\mathrm{n}=7)$. Two-way repeated measure ANOVA, along with Tukey's multiple comparison test displayed non-significant differences $(p>0.99)$ among all the groups

\section{F. asafoetida accelerates motor function recovery}

The motor function recovery was evaluated using SFI, grip strength test (percentage of initial force in $\mathrm{N}$ ), and muscle mass ratio. These parameters are helpful in evaluating the progression of function regained after sciatic nerve injury. Results were statistically evaluated by applying two-way repeated-measures ANOVA. Motor function was significantly improved in $F$. asafoetida chow groups, more than that observed in the control group ( $p=0.007)$. Tukey's multiple comparisons test revealed that
F. asafoetida chow group (200 mg/kg) was significantly more effective in improving SFI at day $6(p=0.02)$, while other treatment groups were found to be non-significant $(p=0.08)$. On day 10 , all treatment groups showed significantly improved SFI ( $p=0.007$ ) as compared to the control group, particularly the $200 \mathrm{mg} / \mathrm{kg}$ treated groups, which showed highly significant $(p=$ 0.0004 ) improvement in SFI (Figure $2 \mathrm{~A}$ ).

(A)

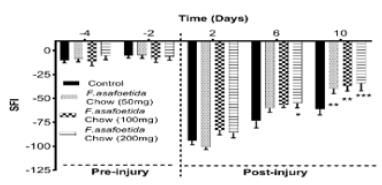

(B)

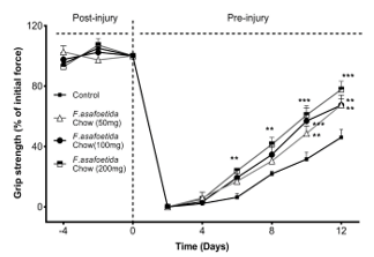

(C)
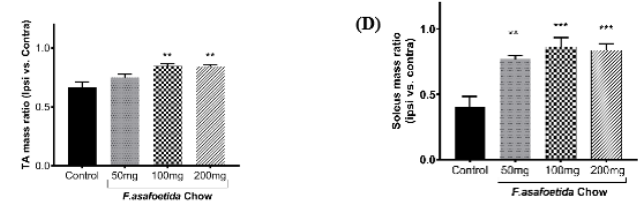

Figure 2: Effect of $F$. asafoetida on motor function recovery. Results are mean \pm SEM; (A) Time course of Sciatic Function Index for mice served with normal chow (control $n=7), F$. asafoetida chow $50 \mathrm{mg}(\mathrm{n}=$ $7), 100 \mathrm{mg}(\mathrm{n}=7)$ and $200 \mathrm{mg}(\mathrm{n}=7)$. The two-way repeated measure ANOVA, along with Tukey's multiple comparison test showed that $F$. asafoetida chow $200 \mathrm{mg}$ significantly improved SFI as compared to the control group on days $6(p=0.02)$ and $10(p=$ 0.0004 ) post-injury. (B) Time course of muscle grip force for mice as in A. The Two-way repeated measure ANOVA, along with Tukey's multiple comparison test showed that $F$. asafoetida chow 200 mg significantly improved grip strength on days 6,8 , 10 and $12(p<0.0001)$ post-injury. (C) TA muscle mass ratio and (D) Soleus muscle mass ratio of groups as in A. Ordinary one-way ANOVA along with Tukey's multiple comparisons tests showed that $F$. asafoetida chow $200 \mathrm{mg}$ significantly increased the muscle mass ratio of TA $(p=0.002)$ and soleus $(p=$ 0.0003 ) as compared to the control group

However, comparative differences among all treatment groups $(50,100$ and $200 \mathrm{mg} / \mathrm{kg}$ ) was found to be non-significant $(p=0.9)$. The grip strength force was significantly augmented in the $F$. asafoetida chow group $(200 \mathrm{mg} / \mathrm{kg})$ at day $6(p$ $=0.0009)$, day $8(p<0.0001)$, day $10(p<$ $0.0001)$ and day $12(p<0.0001)$ post-injury. Similarly, $50 \mathrm{mg} / \mathrm{kg}$ and $100 \mathrm{mg} / \mathrm{kg}$ doses also showed significantly improved grip force $(p=$ 0.007 ) after injury (Figure $2 \mathrm{~B}$ ). The improvement in motor function regain was also confirmed by 
comparing the skeletal muscle mass ratio of all groups. Tibialis anterior (TA) and soleus muscles from both Ipsi and contralateral legs of each animal were dissected and weighed to calculate a mass ratio. TA muscle is a major player, having a significant role in leg functions such as running, walking, and hiking, while the soleus muscle is the part of the calf muscles that aid in running, walking, and maintaining posture balance. The muscle mass ratio of both TA and soleus muscles was significantly improved in $F$. asafoetida chow groups. Particularly, 100mg and 200mg exhibited significant improvement in TA mass ratio $(p=0.002)$ and also exhibited highly significant improvement in soleus muscle mass ratio ( $p=0.0002)$, (Figure $2 \mathrm{C}$ and $\mathrm{D})$.

\section{F. asafoetida hastens sensory function retrieval}

The retrieval of sensory function was evaluated by observing paw withdrawal latency, following a thermal stimulus application. Abrupt paw withdrawal on exposure to hot surface indicates normal sensory functions, while a delay in this withdrawal represents dysfunctional sensory response. F. asafoetida chow group $(200 \mathrm{mg} / \mathrm{kg})$ displayed a significant decrease $(P=0.002)$ in paw withdrawal latency on day 6 and day 9 postinjury. However, on day 9 post-injury, all $F$. asafoetida chow groups (50 mg, $100 \mathrm{mg}$, and $200 \mathrm{mg}$ ) displayed a significant decrease $(P=$ 0.005) in paw withdrawal latency time as compared to the control group (Figure 3).

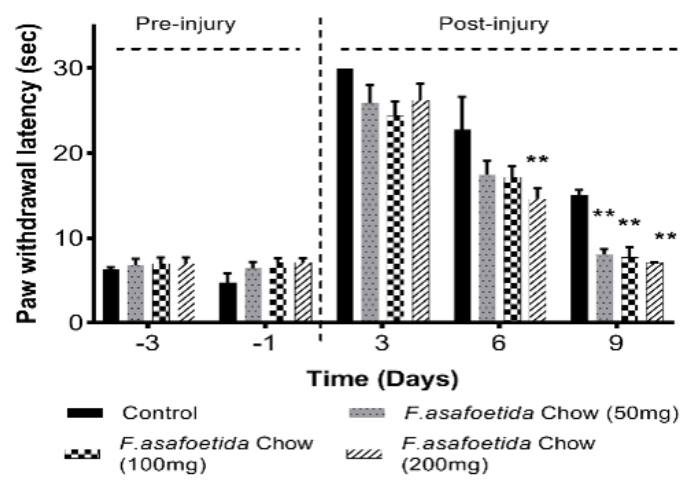

Figure 3: Effect of $F$. asafoetida on sensory function recovery. Results are mean $\pm S E M$; Measurement of paw withdrawal latency of mice served with normal chow (control $\mathrm{n}=7$ ), $F$. asafoetida chow $50 \mathrm{mg}(\mathrm{n}=$ $7), 100 \mathrm{mg}(\mathrm{n}=7)$ and $200 \mathrm{mg}(\mathrm{n}=7)$. Two-way repeated measure ANOVA, along with Tukey's multiple comparison test showed that $F$. asafoetida chow $200 \mathrm{mg}$ significantly decreased the paw withdrawal latency time as compared to control on day 6 and $9\left({ }^{* *} p=0.002\right)$ post-injury

Influence of $\boldsymbol{F}$. asafoetida on systemic indices
It is believed that glucose levels can modulate the equilibrium between anti-oxidative and oxidative progressions, and hyperglycemiainduced oxidative stress is an eminent factor for the development of numerous pathologies [14]. Here, F. asafoetida chow group (200 mg/kg) presented a highly significant amelioration $(\mathrm{P}=$ 0.0005) in the glycemic level compared to that which was recorded before starting $F$. asafoetida supplementation (Figure $4 \quad \mathrm{~A}$ ). These observations are in accordance with reported data on the antidiabetic effects of this plant.

The TAC assay was carried out to measure the level of antioxidants in the biological samples. The addition of $F$. asafoetida to the feed significantly enhanced the TAC $(P<0.0001)$ (Figure $4 \mathrm{~B}$ ), and similarly, the TOS level was significantly reduced $(P=0.01)$ in $F$. asafoetida chow $(200 \mathrm{mg} / \mathrm{kg})$ as shown in Figure $4 \mathrm{C}$.

(A)

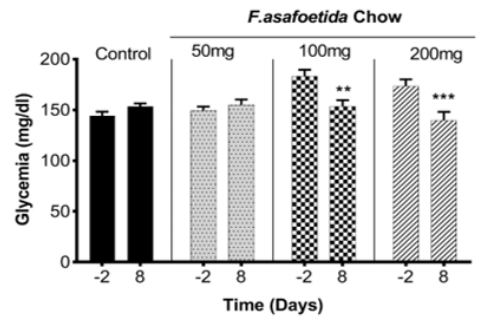

(B)

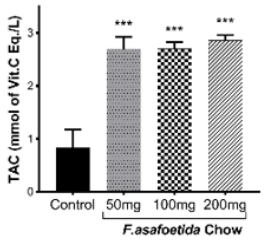

(C)

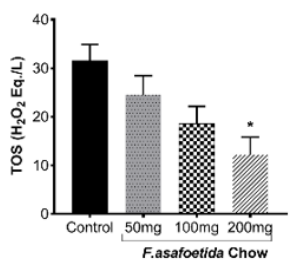

Figure 4: Effect of $F$. asafoetida on glycemic and oxidative stress levels. Results are mean \pm SEM; (A) Measurement of glycemic level in mice served with normal chow (control $\mathrm{n}=7$ ), $F$. asafoetida chow $50 \mathrm{mg}$ $(n=7), 100 \mathrm{mg}(\mathrm{n}=7)$ and $200 \mathrm{mg}(\mathrm{n}=7)$. The glycemic level was measured 2 days before, and then 8 days after inducing injury. Two-way repeated measure ANOVA along with Sidak's multiple comparisons tests showed a highly significant decrease in glycemic level for $F$. asafoetida chow 200 mg $\left({ }^{* *} P=0.0005\right)$. (B) Total antioxidant capacity measured in mice as in A. One-way repeated measure ANOVA along with Tukey's multiple comparisons test showed highly significant differences $\left({ }^{* * *} p<0.0001\right)$ for all $F$. asafoetida chow groups. (C) Total oxidant status measured in animals as in A. One-way repeated measure ANOVA along with Tukey's multiple comparisons test presented significant differences ( ${ }^{*} \mathrm{P}$ $=0.01$ ) for $F$. asafoetida chow $200 \mathrm{mg}$ group 


\section{DISCUSSION}

The PNI is one of the most common and lifethreatening conditions with a wide range of symptoms that affect a large number of young people worldwide. The situation appears worse in developing countries where violations of traffic rules are common. After an injury to the peripheral nerve, a cascade of the regulatory process commences to clear the damaged tissues and to initiate the nerve-repairing process. However, the rate of this process is so sluggish that it takes several weeks or even years to be accomplished. Meanwhile, the commencement of muscular atrophy causes further delay in function retrieval [15]. Therefore, speeding up the rate of nerve regeneration and associated function recovery is requisite before the onset of muscle atrophy. Despite the availability of extensive work on PNI and its related mechanisms, reliable treatments offering complete function recovery are still inadequate. Although neuroprotective properties of $F$. asafoetida have already been investigated, there is no information of its effects on the process of function rehabilitation after PNI.

The Ferula genuses belong to the family, Umbelliferae, and they are taken as rich sources of beneficial bioactive compounds [16]. Ferula asafoetida is used as an antihelminthic, antispasmodic, and carminative agent in Iranian folk medicine system [17]. It also exhibits relief in bronchitis, stomach ache, whooping cough, indigestion, and asthma [16]. Some other reports indicate that this plant also shows the potency to upsurge sexual hunger [18]. Based on these interesting data, the present study was intended to discover the role of $F$. asafoetida in accelerating function retrieval following sciatic nerve injury. Generally, the addition of any material in animal feed may alter the smell and taste, and causes modified eating patterns. To elude the interference of such an ambiguous eating pattern, feed consumption and body mass were observed daily during the course of the trial. It was found that $F$. asafoetida addition modified neither feed intake and nor body mass. The restoration of motor function is dependent on the speed of nerve regeneration and quantity of motor units elevating innervation to the target muscle. That becomes evident in improved SFI value and muscle grip strength. $F$. asafoetida $(200 \mathrm{mg} / \mathrm{kg}$ ) treated animals manifested an early recovery both in motor and sensory aspects. Following an injury, electrical impulses are interrupted, which leads to muscle mass decline that can be restored on reinnervation. So, muscle mass ratio is a reliable parameter associated with the determination of function recovery $[10,19,20]$. The mass of both TA and soleus muscles appeared remarkably improved in $F$. asafoetida treated animals. Similarly, ameliorated sensory function was also observed at the early stage, and this effect was prominent at a higher dose of $F$. asafoetida $(200 \mathrm{mg} / \mathrm{kg})$. These findings suggest that $F$. asafoetida might be more effective in accelerating function recovery at higher doses.

In a study on rats, it has been reported that the aqueous extract of $F$. asafoetida (oleo gum resins) exhibits an anti-hyperglycemic effect [21]. Moreover, another study showed that the $F$. asafetida, at both doses of 200 and $400 \mathrm{mg} / \mathrm{kg}$ body weight, presented anti-diabetic activity (decreased FBS levels) after 14 days of treatment [22]. The findings of this study indicate a similar effect of $F$. asafoetida on the blood glucose on the $8^{\text {th }}$ day of treatment.

It is believed that oxidative stress stands as a leading mediator of pathogenesis of all major diseases including nerve injury. Oxidative stress initiates the mitochondrial dysfunction and causes neuronal damage, apoptosis, neuroinflammation, and demyelination, whereas lower TOS and higher TAC levels improve functional recovery following $\mathrm{PNI}$ [23]. F. asafoetida also possesses significant antioxidant capacity in both in-vitro and in-vivo studies at 200 and $400 \mathrm{mg} / \mathrm{kg}$ doses [7,22]. Accordingly, the addition of $F$. asafoetida in the feed of mice significantly up-regulated the TAC and attenuated the level of TOS. These findings are concomitant with the already documented characteristics of this plant. Based on these findings, it can be summed up that $F$. asafoetida can prove an interesting drug candidate to combat the problem of injuries to the nervous system. Future extensive and detailed trials can unravel this mystery.

\section{CONCLUSION}

The findings of the present work indicate that $F$. asafoetida (oleo gum resin) has the potential to accelerate sensory motor functions regain following a mechanically induced insult to a peripheral nerve. $F$. asafoetida exhibits remarkable advantages at a dose of $200 \mathrm{mg} / \mathrm{kg}$. Further investigations are needed in this direction for the identification, isolation and characterization of bioactive molecule that actually bestows these observed effects.

Trop J Pharm Res, September 2020; 19(9): 1908 


\section{DECLARATIONS}

\section{Acknowledgement}

This work was made possible by the financial support of the Higher Education Commission of Pakistan (Grant no. 7612/Punjab/NRPU/R\&D/ HEC/2017 to Dr. Ghulam Hussain).

\section{Conflict of interest}

The authors declare that no conflict of interest is associated with this work.

\section{Contribution of authors}

We declare that this work was done by the authors named in this article and all liabilities pertaining to claims relating to the content of this article will be borne by the authors. G.H, H.A., and A.R. designed the experiments and experimental design; S.K.S.K., A.R., and N.A., performed the experiments; G.H analyzed the data; K.S.U., S.A.M, and N.B. contributed reagents/materials/analysis tools; G.H and A.R actively participated in writing the draft of this manuscript.

\section{Open Access}

This is an Open Access article that uses a funding model which does not charge readers or their institutions for access and distributed under the terms of the Creative Commons Attribution License (http://creativecommons.org/licenses/by/ 4.0) and the Budapest Open Access Initiative (http://www.budapestopenaccessinitiative.org/rea d), which permit unrestricted use, distribution, and reproduction in any medium, provided the original work is properly credited.

\section{REFERENCES}

1. Rasul A, Al-shawi AAA, Malik SA, Anwar H, Rasool B, Razzaq A, Aziz N, Kashif S, Kamran S, Sarfraz I. Neurada procumbens promotes functions regain in a mouse model of mechanically induced sciatic nerve injury. Pak. J. Pharm. Sci 2019; 32(4): 1761-1766

2. Hussain G, Wang J, Rasul A, Anwar H, Qasim M, Zafar S, Aziz N, Razzaq A, Hussain R, de Aguilar JLG et al. Current Status of Therapeutic Approaches against Peripheral Nerve Injuries: A Detailed Story from Injury to Recovery. Int. J. Biol. Sci 2020; 16(1): 116-134

3. Hussain G, Huang J, Rasul A, Anwar $H$, Imran A, Maqbool J, Razzaq A, Aziz N, Makhdoom E, Komuk M et al. Putative Roles of Plant-Derived Tannins in Neurodegenerative and Neuropsychiatry Disorders: An Updated Review. Molecules 2019; 24(12): 2213
4. Hussain G, Zhang L, Rasul A, Anwar H, Sohail MU, Razzaq A, Aziz N, Shabbir A, Muhammad Ali, Sun T. Role of plant-derived flavonoids and their mechanism in attenuation of Alzheimer's and Parkinson's diseases: An update of recent data. Molecules 2018; 23(4): 1-26

5. Hussain G, Rasul A, Anwar H, Aziz N, Razzaq A, Wei W, Ali M, Li J, Li X. Role of plant derived alkaloids and their mechanism in neurodegenerative disorders. Int. J. Biol. Sci 2018; 14(3): 341-357

6. Imran A, Xiao L, Ahmad W, Anwar H, Rasul A, Imran M, Aziz N, Razzaq A, Arshad $M U$, Shabbir $A$, et al. Foeniculum vulgare (Fennel) promotes functional recovery and ameliorates oxidative stress following a lesion to the sciatic nerve in mouse model. J. Food Biochem 2019; 43(9): e12983

7. Mallikarjuna GU, Dhanalakshmi S, Raisuddin S, Rao AR. Chemomodulatory influence of Ferula asafoetida on mammary epithelial differentiation, hepatic drug metabolizing enzymes, antioxidant profiles and $\mathrm{N}$ methyl-N-nitrosourea-induced mammary carcinogenesis in rats. Breast Cancer Res. Treat 2003; 81: 1-10

8. Veyrac A, Sacquet J, Nguyen V, Marien M, Jourdan F, Didier $A$. Novelty determines the effects of olfactory enrichment on memory and neurogenesis through noradrenergic mechanisms. Neuropsychopharmacology 2009; 34(3): 786-795

9. Khazdair MR, Anaeigoudari A, Hashemzehi $M$, Mohebbati R. Neuroprotective potency of some spice herbs, a literature review. J. Tradit. Complement. Med 2019; 9(2): 98-105.

10. Aziz N, Rasul A, Malik SA, Anwar H, Imran A, Razzaq A, Shaukat A, Kashif S, Kamran S, Aguilar JG, et al. Supplementation of Cannabis sativa $L$. leaf powder accelerates functional recovery and ameliorates haemoglobin level following an induced injury to sciatic nerve in mouse model. Pak. J. Pharm. Sci 2019; 32(2): 785-792

11. Haas JS, Viana AF, Heckler M, Poser AP, Von GL, Kuze Rates SM. The antinociceptive effect of a benzopyran (HP1) isolated from hypericum polyanthemum in mice hot-plate test is blocked by naloxone. Planta Med 2010; 76(13): 1419-1423

12. Hussain G, Schmitt $F$, Henriques A, Lequeu T, Rene F, Bindler F, Dirrig-Grosch S, Oudart H, Palamiuc L, MetzBoutigue $\mathrm{MH}$, et al. Systemic Down-Regulation of Delta9 Desaturase Promotes Muscle Oxidative Metabolism and Accelerates Muscle Function Recovery following Nerve Injury. PLoS One 2013; 8(6): e64525

13. Asmat $U$, Abad $K$, Ismail $K$. Diabetes mellitus and oxidative stress-A concise review Saudi Pharm. J 2016; 24(5): 547-553

14. King GL, Loeken MR. Hyperglycemia-induced oxidative stress in diabetic complications. Histochem. Cell Biol 2004; 122(4): 333-338

15. Razzaq A, Hussain G, Rasul A, Xu J, Zhang Q, Malik SA, Anwar H, Aziz N, Braidy N, de Aguilar JLG, et al. Strychnos nuxvomica $L$. seed preparation promotes functional recovery and attenuates oxidative stress in a

Trop J Pharm Res, September 2020; 19(9): 1909 
mouse model of sciatic nerve crush injury BMC Complement Med Ther 2020; 20: 1-11

16. Iranshahy $M$, Iranshahi $M$. Traditional uses, phytochemistry and pharmacology of asafoetida (Ferula assafoetida oleo-gum-resin) - A review. J Ethnopharmacol 2011; 134: 1-10

17. Bagheri SM, Sahebkar A, Gohari AR, Saeidnia S, Malmir $M$, Iranshahi $M$. Evaluation of cytotoxicity and anticonvulsant activity of some Iranian medicinal Ferula species. Pharm. Biol 2010; 48: 242-246

18. Bagheri S, Mohamadsadeghi $H$, Hejazian $E$. Antinociceptive effect of seed's essential oil of Ferula assafoetida in Mice Int J Clin Exp Physiol 2017; 4: 34

19. Tuffaha $S H$, Budihardjo JD, Sarhane KA, Khusheim $M$, Song $D$, Broyles JM, Salvatori R, Means KR, Higgins JP, Shores JT. Growth Hormone Therapy Accelerates Axonal Regeneration, Promotes Motor Reinnervation, and Reduces Muscle Atrophy following Peripheral Nerve Injury. Plast. Reconstr Surg 2016; 137: 1771-1780
20. Li QT, Zhang PX, Yin XF, Han N, Kou YH, Deng JX, Jiang BG. Functional recovery of denervated skeletal muscle with sensory or mixed nerve protection: $A$ pilot study PLoS One 2013; 8 (11): e79746

21. Akhlaghi F, Rajaei Z, Hadjzadeh MAR, Iranshahi M, Alizadeh M. Antihyperglycemic effect of asafoetida (Ferula assafoetida oleo-gum-resin) in streptozotocininduced diabetic rats. World Appl Sci J 2012; 17: 157162

22. Yusufoglu HS, Soliman GA, Abdel-Rahman RF, AbdelKader MS, Ganaie MA, Bedir E, Erel SB, Öztürk B. Antihyperglycemic and antihyperlipidemic effects of ferula assafoetida and ferula tenuissima extracts in diabetic rats. Pakistan J Biol Sci 2015; 18(7): 314-323

23. Areti A, Yerra VG, Naidu VGM, Kumar A. Oxidative stress and nerve damage: Role in chemotherapy induced peripheral neuropathy. Redox Biol 2014; 2(1): 289-29528

24. National Institute of Health. Guide for the Care and Use of Laboratory Animals 1978. 